\section{$\underset{\substack{\text { hommes } \\ \text { \& migrations }}}{ }$}

\section{Hommes \& migrations}

Revue française de référence sur les dynamiques

migratoires

1302 | 2013

Le Japon, pays d'immigration?

\title{
Auteurs coréens ou d'origine coréenne vivant au Japon
}

\section{Hélène Le Bail}

\section{(2) OpenEdition \\ Journals}

\section{Édition électronique}

URL : http://journals.openedition.org/hommesmigrations/2512

DOI : $10.4000 /$ hommesmigrations. 2512

ISSN : 2262-3353

\section{Éditeur}

Musée national de l'histoire de l'immigration

\section{Édition imprimée}

Date de publication : 1 avril 2013

Pagination : 188-189

ISBN : 978-2-919040-22-3

ISSN : $1142-852 X$

\section{Référence électronique}

Hélène Le Bail, « Auteurs coréens ou d'origine coréenne vivant au Japon », Hommes \& migrations [En ligne], 1302 | 2013, mis en ligne le 13 septembre 2013, consulté le 22 septembre 2020. URL : http:// journals.openedition.org/hommesmigrations/2512 ; DOI : https://doi.org/10.4000/ hommesmigrations. 2512

Ce document a été généré automatiquement le 22 septembre 2020.

Tous droits réservés 


\title{
Auteurs coréens ou d'origine coréenne vivant au Japon
}

\author{
Hélène Le Bail
}

1 Parmi les auteurs coréens ou d'origine coréenne vivant au Japon et s'exprimant en japonais, deux ont été traduits en français. Le Berceau au bord de l'eau ${ }^{1}$ est le roman le plus autobiographique de Yu Miri, qu'elle publia en 1997 alors âgée de 29 ans. Yan Sogiru avait, lui, 62 ans lorsqu'il sortit son roman Sang et os inspiré de l'histoire de sa famille au Japon. Sang et os ${ }^{2}$ a été adapté à l'écran par Sai Yôichi en 2004 avec Takeshi Kitano dans le rôle principal.

2 Ils sont tous les deux Coréens du Japon de deuxième génération. L'une a grandi à Yokohama et l'autre à Osaka, deux villes qui abritent encore aujourd'hui d'importantes communautés coréennes. Le roman de Yu Miri est un récit introspectif au fil de souvenirs d'enfance dans une famille dont elle cherche à recoller les différentes versions des raisons de l'immigration dans les années d'après-guerre: idéologie politique, petits trafics, dissensions familiales, grossesse hors mariage. Le passage plus ou moins clandestin au Japon de ses grands-parents maternels et de son père illustre le caractère souvent complexe du départ. Le Berceau au bord de l'eau est aussi, comme beaucoup de ses autres œuvres, une réflexion sur l'identité des Coréens du Japon.

De même, dans Sang et os, les personnages ont fait le voyage entre la Corée et le Japon à l'époque coloniale pour des raisons très diverses: mariages malheureux, discriminations internes à la Corée, pauvreté. Très différent de l'ouvrage intimiste de Yu Miri, le roman de Yan Sogiru est une fresque d'un demi-siècle de la communauté coréenne à Osaka. Centré sur la figure d'un personnage brutal, Kim Junpyeong, l'auteur fait se croiser les vies de femmes coréennes à la fois entreprenantes et soumises aux normes traditionnelles du mariage, d'activistes coréens, mais aussi d'enfants coréens ou métis de la deuxième génération. Cette épopée familiale aborde la question du travail - exploitation des Coréens à l'époque coloniale et entreprenariat ethnique aux lendemains de la guerre -, celle de l'engagement politique - depuis les premières mobilisations collectives contre les discriminations coloniales jusqu'à la promotion des “retours" en Corée du Nord dans les années 1960. Elle propose le regard d'une minorité 
nationale sur les grands temps de l'histoire, telles la dépression économique des années 1930, la guerre du Pacifique et la décolonisation.

Dans les deux ouvrages, la question du nom se pose, emblématique à la fois du regard porté par les gouvernants sur la population coréenne et des hésitations des Coréens entre assimilation et revendication de leur identité. Dans le roman de Yan Sogiru, les personnages utilisent entre eux leur nom coréen, mais les Japonais les appellent selon la prononciation japonaise des caractères de leur nom. Dans la dernière période de la colonisation, le Japon décida dans le cadre de sa politique d'assimilation d'attribuer à chacun un nom de famille japonais afin d'affirmer formellement son appartenance à l'empire. Ainsi, le personnage principal du roman, Kim Junpyeong, devient Kanamoto Shunpei. Pendant longtemps, après la guerre, la naturalisation japonaise supposait l'adoption d'un nom japonais. Même non naturalisés, un certain nombre de Coréens continuent d'utiliser un nom japonais dans la vie courante afin d'éviter les discriminations.

5 Le nom est souvent le dernier élément qui permet de distinguer les Coréens de deuxième ou troisième génération et, face aux discriminations, beaucoup ont cherché à rester invisibles tout en essayant de maintenir au sein du foyer leur culture d'origine. Le récit de Yu Miri s'ouvre précisément par une analyse de son nom. Son grand-père, qui décida de son prénom, a choisi des caractères qui se prononçaient de la même façon en japonais et en coréen. Par chance, le caractère de son nom de famille pouvait aussi passer pour un nom de famille japonais : "Supposons que j'aie eu un nom hurlant le Coréen, comme Kim quelque chose, par exemple, il est probable que le cours de ma vie aurait été fort différent de ce qu'il est actuellement." Pourtant, à ses débuts dans le théâtre, entre la prononciation coréenne, Yu, et la japonaise, Yanagi, elle opte pour Yu, et choisit donc que ses origines coréennes soient visibles dans la société japonaise.

\section{NOTES}

1. Yu Miri, Le Berceau au bord de l'eau, Arles, éd. Philippe Picquier, coll. "Japon", 2000, 224 p., traduit par Jean Campignon,

2. Yan Sogiru, Sang et os, Monaco, éd. du Rocher, coll. "Série japonaise", 2011, 560 p., traduit par Ryoko Sekiguchi et Patrick Honnoré. 